\begin{tabular}{|c|l|}
\hline Title & $\begin{array}{l}\text { Significance of peristaltic squeezing of sperm bundles in the silkworm, Bombyx mori: elimination of irregular eupyrene } \\
\text { sperm nuclei of the triploid }\end{array}$ \\
\hline Author(s) & Sahara, Ken; Kawamura, Naoko; Y amashiki, Naoko; Saitoh, Hiroshi \\
\hline Citation & $\begin{array}{l}\text { Zygote, 9(2), 159-166 } \\
\text { https://doi.org/10.1017/S0967199401001174 }\end{array}$ \\
\hline Issue Date & 2001-05 \\
\hline Doc URL & http://hdl.handle.net/2115/849 \\
\hline Rights & Copyright (c) 2001 Cambridge University Press \\
\hline Type & article \\
\hline File Information & Zygote 9 (May) Sahara, K..pdf \\
\hline
\end{tabular}

Instructions for use 


\title{
Significance of peristaltic squeezing of sperm bundles in the silkworm, Bombyx mori: elimination of irregular eupyrene sperm nuclei of the triploid
}

\author{
Naoko Kawamura ${ }^{1}$, Naoko Yamashiki ${ }^{1}$, Hiroshi Saitoh ${ }^{2}$ and Ken Sahara ${ }^{3}$ \\ Rakuno Gakuen University, Ebetsu and Hokkaido University, Sapporo, Japan
}

Date submitted: 11.9.00. Date accepted: 15.11 .00

\section{Summary}

\begin{abstract}
Silkworm (Lepidoptera) males produce dimorphic sperm: nucleate eupyrene sperm and anucleate apyrene sperm. The eupyrene sperm are ordinary sperm to fertilise the eggs, while the function of apyrene sperm remains uncertain. After meiosis, 256 sperm cells are enclosed by a layer of cyst cells, forming a sperm bundle. We have previously documented that the nucleus of eupyrene sperm anchors to the head cyst cell, which locates at the anterior apex of the bundle, by an acrosome tubule-basal body assembly. Neither the basal body attachment to the nucleus nor the acrosome is seen in apyrene sperm, and the nuclei remain in the middle region of the bundle. Peristaltic squeezing starts from the anterior of the bundles in both types of sperm, and cytoplasmic debris of the eupyrene sperm, and both the nuclei and debris of apyrene sperm, are eliminated at the final stage of spermatogenesis. Since the irregularity of meiotic division in apyrene sperm is known, we used triploid silkworm males that show irregular meiotic division even in eupyrene spermatocytes and are highly sterile. The irregular nuclei of the triploid are discarded by the peristaltic squeezing just as those of the apyrene sperm. Transmission electron microscopic observations disclose the abnormality in the acrosome tubule and in the connection to the basal body. The peristaltic squeezing of sperm bundles in the silkworm appears to be the final control mechanism to eliminate irregular nuclei before they enter female reproductive organs.
\end{abstract}

Keywords: Apyrene sperm, Eupyrene sperm, Peristaltic squeezing, Spermatogenesis, Triploid silkworm

\section{Introduction}

In Lepidoptera, nucleate eupyrene sperm (eusperm) are the ordinary sperm used to fertilise the eggs. On the other hand, the function and significance of anucleate apyrene sperm (parasperm), which are produced in numbers 4 times greater than the eupyrene sperm, are still uncertain (Friedländer, 1997; Jamieson, 1987; Jamieson et al., 1999), though they seem to have a defi-

All correspondence to: N. Kawamura, Biological Laboratory, Rakuno Gakuen University, Ebetsu 069-8501, Japan. Tel: +81 11388 4736. Fax: +81 11386 1989. e-mail: yij00132@nifty. ne.jp ${ }^{1}$ Biological Laboratory, Rakuno Gakuen University, Ebetsu 069-8501, Japan.

${ }^{2}$ Experimental Farm, Faculty of Agriculture, Hokkaido University, Sapporo 060-0811, Japan.

${ }^{3}$ Department of Applied Bioscience, Graduate School of Agriculture, Hokkaido University, Sapporo 060-8589, Japan. nite role in fertilisation (Cook \& Wedell, 1999; Takemura et al., 1999). We have found marked morphological differences between the two types of the sperm in the process of spermatogenesis, including the behaviour of the nucleus, centriole, basal body, axoneme, mitochondria and acrosome (Yamashiki \& Kawamura, 1997, 1998; Kawamura et al., 1998). Furthermore, one of the marked differences between spermatogenesis in the two types of sperm is irregular meiosis in the apyrene spermatocytes (Wolf \& Bastmeyer, 1991).

As previously reported (Kawamura et al., 2000), peristaltic squeezing starts from the anterior end of the sperm bundle at the final stage of spermatogenesis in both types of sperm. Following the squeezing action, the nuclei of the eupyrene sperm remain in the anterior region, and only the cytoplasmic debris is ejected from the posterior end of the bundle. On the other hand, the nuclei of apyrene sperm are squeezed out together with the cytoplasmic debris. We named this phenomenon 'peristaltic squeezing'. Transmission electron 
microscopic (TEM) observations by Yamashiki \& Kawamura (1997) disclosed that, in the eupyrene sperm bundle, the basal body attaches to the nucleus and an acrosome tubule connects to the basal body, forming an acrosome tubule-basal body assembly. The anterior part of the acrosome tubule penetrates deep into the head cyst cell that locates at the apex of the bundle as though it fixes the nucleus to the anterior region of the bundle. Apyrene sperm possess no acrosome and no basal body attachment to the nuclei, so the nuclei remain in the middle region of the bundle. The fixation of the nuclei to the anterior region in the eupyrene bundle appears to be an important way of protecting the nuclei against the squeezing action.

Polyploid animals are quite rare and Muller (1925) considered this to be due to the imbalance of sex chromosomes. They are often associated with parthenogenic reproduction (Lokki \& Saura, 1980; Gillies, 1989). No bisexual polyploids have been described in Order Insecta (Lokki \& Saura, 1980). One of the advantages of the silkworm as an experimental material is the ease with which bisexual tetraploid individuals can be induced by various chemical and physical treatments (Tazima, 1964). Since the female autotetraploids produced by low temperature treatment (Kawamura, 1978, 1979) have normal fertility, triploids can be obtained from the cross between a tetraploid female and a diploid male. Triploid spermatocytes of the silkworm form trivalents and univalents in addition to bivalents in meiosis I (Sahara et al., 1990). A dramatic reduction in fertility occurs in triploid silkworm males, possibly due to the irregularity in meiosis (Kawaguchi, 1936). In this study, we compared eupyrene spermatogenesis of the triploid silkworm with that of the diploid and discuss the role of peristaltic squeezing in reproduction.

\section{Materials and methods}

The strains of the silkworm (Bombyx mori) used were re9 females (red egg: re/re) and Tw1 males (white egg 2: $w-2 / w-2)$ for tetraploid induction (Kawamura, 1978), rs males (sex-linked chocolate, red egg: sch/sch, re/re) for triploid production, and Cre (sex-limited sable, red egg: T(W:2) $\left.p^{S a}, r e / r e\right)$ females for examining the fertility of the triploid males. $F_{1}$ eggs of the cross between a red egg strain and a white egg 2 strain show wild-type colour (black) and the egg colour segregation ratio in the $F_{2}$ is black:red:white $=9: 3: 4$.

\section{Induction of polyploid silkworms}

\section{Tetraploid}

$F_{1}$ eggs of the cross between an re9 female and a Tw1 male at the first cleavage stage (120-150 min after oviposition) were refrigerated at $-10{ }^{\circ} \mathrm{C}$ for $24 \mathrm{~h}$ and returned to room temperature. The eggs with large serosa nuclei were selected as the tetraploid (Kawamura, 1979).

\section{Triploid}

Since the meiotic chromosomes in the female silkworm perform no crossing over, the tetraploid female is as fertile as the diploid. Triploid silkworms were obtained by the cross between a tetraploid female and an rs male with almost $100 \%$ hatchability and with normal growth rate. Triploidy of the progeny was confirmed by an egg colour segregation ratio of black to red of 5 to 1.

\section{Indirect immunofluorescence staining for tubulin}

As described in detail previously (Yamashiki \& Kawamura, 1997; Kawamura et al., 2000), spermatocysts and sperm bundles from excised testes of fifth-instar larvae and pupae were smeared on a coverslip coated with 3aminopropyl-triethoxy-silane (Sigma Chemical, St. Louis, MO) and fixed in $4 \%$ paraformaldehyde in phosphate-buffered saline (PBS, pH 7.0) for $1 \mathrm{~h}$. Mouse monoclonal antibody against chicken alpha-tubulin (Cederlane Laboratory, Hornby, Ontario, Canada), which is cross-hybridised with Bombyx alpha-tubulin, and fluorescein isocyanate-conjugated goat antimouse IgG (MBL, Tokyo, Japan) with propidium iodide (Sigma) was applied on the coverslip. The coverslip was mounted on a glass slide with $90 \%$ glycerinDABCO (Sigma) mountant. The stained cells were observed with a laser scanning confocal microscope (Fluoview, Olympus, Tokyo, Japan).

\section{Transmission electron microscopy}

Silkworm testes were fixed in $3 \%$ glutaraldehyde in 0.1 M PBS for $2 \mathrm{~h}$, and in the same solution containing $0.2 \%$ tannic acid for an additional $1 \mathrm{~h}$ at room temperature. After the specimens had been rinsed three times with PBS and postfixed in $1 \% \mathrm{OsO}_{4} / \mathrm{PBS}$, they were stained en bloc in $0.5 \%$ uranyl acetate. They were embedded in Quetol 812. Thin sections were stained with uranyl acetate and lead citrate, and examined with an electron microscope (H-800, Hitachi, Tokyo, Japan). 


\section{Results}

\section{Fertility of triploid males}

The fertility of triploid males was examined by mating with Cre females in two separate experimental groups $(n=15$ and 14$)$. The fertility was $0.26 \%$ in group 1 and $0.19 \%$ in group 2 (Table 1 ). Total fertility of $0.23 \%$ in triploid males indicated high sterility when compared with that in the diploid control $(97.75 \%)$.

Table 1 Fertility of triploid and diploid males

\begin{tabular}{|c|c|c|c|c|c|}
\hline \multirow{2}{*}{$\begin{array}{l}\text { Experimental } \\
\text { groups }\end{array}$} & \multirow[t]{2}{*}{$n$} & \multicolumn{2}{|c|}{ Fertilised eggs ${ }^{* a}$} & \multicolumn{2}{|c|}{ Unfertilised Fertility } \\
\hline & & Black & Red & eggs & $(\%)$ \\
\hline Triploid 1 & 15 & 13 & 2 & 5821 & 0.26 \\
\hline Triploid 2 & 14 & 7 & 1 & 4224 & 0.19 \\
\hline Diploid (control) & l) 2 & 477 & 523 & 23 & 97.75 \\
\hline
\end{tabular}

${ }^{a}$ Fertilised eggs in backcross with Cre females (red egg strain) segregate into black and red eggs (see Materials and Methods).

\section{Eupyrene and apyrene spermatogenesis in the diploid $(2 n=56)$}

In eupyrene cells, chromosome separation proceeded normally and no chromosome bridges were seen in either primary (Kawamura, 1994) or secondary meioses (Fig. 1A). On the other hand, apyrene spermatocytes produced a feeble spindle and the chromosome separation was irregular with thick chromosome bridges (Fig. 1B). The apyrene spermatid nuclei were of various sizes, probably due to deficiency, translocation or failure of chromosome separation. The nuclei were discarded from the posterior end by peristaltic squeezing. Fig. $1 \mathrm{E}$ and $\mathrm{F}$ show a diploid eupyrene sperm bundle at the squeezing stage. The nuclei remained in the anterior (Fig. 1E), while cytoplasmic debris, in which no nuclear fragments were contained, was squeezed out from the posterior end of the bundle (Fig. 1F).

\section{Eupyrene and apyrene spermatogenesis in the triploid $(3 n=84)$}

The primary eupyrene spermatocytes at metaphase showed univalent, bivalent and trivalent chromosomes (Sahara et al., 1990). The irregularity of chromosome separation was displayed as chromosome bridges between daughter nuclei in anaphase and telophase. Since the chromosome bridges were emphasised in the second meiotic division, we visualised the anaphase and telophase figures in the secondary spermatocytes (Fig. 1C, D). In contrast to the diploid eupyrene spermatocytes, many chromosome bridges were observed at anaphase and telophase in the triploid cells (Fig. 1C). The chromosome separation in the apyrene spermatocytes was as irregular as in the diploids (Fig. 1D). The sperm nuclei of the triploid eupyrene sperm bundle remained in the anterior region before peristaltic squeezing and young sperm bundles appeared almost as normal as diploid ones. Regardless of the ploidy, the eupyrene sperm bundles started peristaltic squeezing after pupation. Fig. 1G-I show the squeezing process in the triploid eupyrene sperm bundle. The sperm nuclei were larger than in the diploid and cyst cells were much thicker. At the time of squeezing, the sperm nuclei gradually receded towards the posterior (Fig. 1G-I). As the squeezing proceeded, the recession of nuclei in the sperm bundle became remarkable (Fig. $1 \mathrm{H}$ ), and none or only a few nuclei remained in the anterior of the sperm bundle (Fig. 1I). Spearhead-shaped sperm nuclei changed their shape during the process, usually becoming round or fragmented, and were discarded from the posterior end of the bundle. The debris contained many nuclear fragments in addition to a few round nuclei (Fig. 1J). The appearance of the apyrene sperm bundle was similar to that of the diploid. The nuclei that maintained a round shape were discarded from the bundle by peristaltic squeezing.

\section{TEM observation of eupyrene sperm bundles during squeezing in the diploid and triploid}

In diploid eupyrene spermiogenesis, the nuclei moved to the anterior of the spermatocyst, where the spherical nuclei transformed to a spearhead shape. TEM observation revealed that the basal body attached to the nucleus and an acrosome tubule that connected to the basal body extended deep into the head cyst cell (Yamashiki \& Kawamura, 1997). Fig. 2A shows the head cyst cell region of a diploid sperm bundle at the early peristaltic squeezing stage. An acrosome tubule extended towards the apical surface (Fig. 2B). The base of the acrosome tubule connected with the basal body, which attached to the sperm nucleus (Fig. 2C).

Fig. 3A shows a triploid eupyrene sperm bundle that was comparable to the diploid one in Fig. 2A. Triploid nuclei were larger and the acrosome tubules were sparse in the head cyst cell. TEM observation of a sperm bundle during peristalsis at a higher magnification disclosed the abnormal figures, that is, the extension of the acrosome tubule in the wrong direction (Fig. 3B) or the failure in the acrosome tubule-basal body connection (Fig. 3C). Such figures were common in the triploid sperm bundles at the stage of peristaltic squeezing. As the nuclei receded towards the posterior of the bundle, they lost their spearhead shape. In some nuclei, constrictions appeared across the long axis. Chromatin was highly condensed (Fig. 4A), or became 

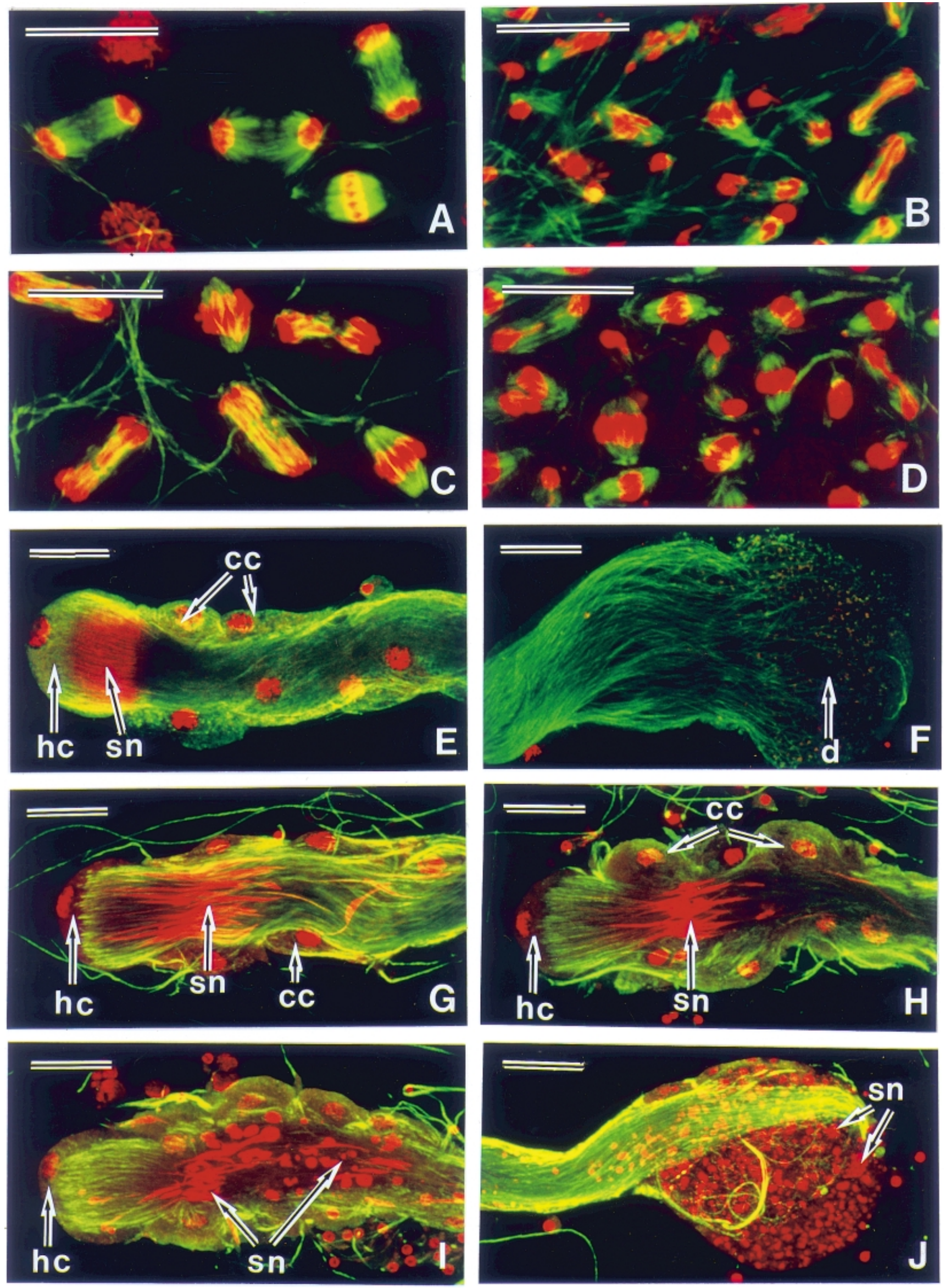

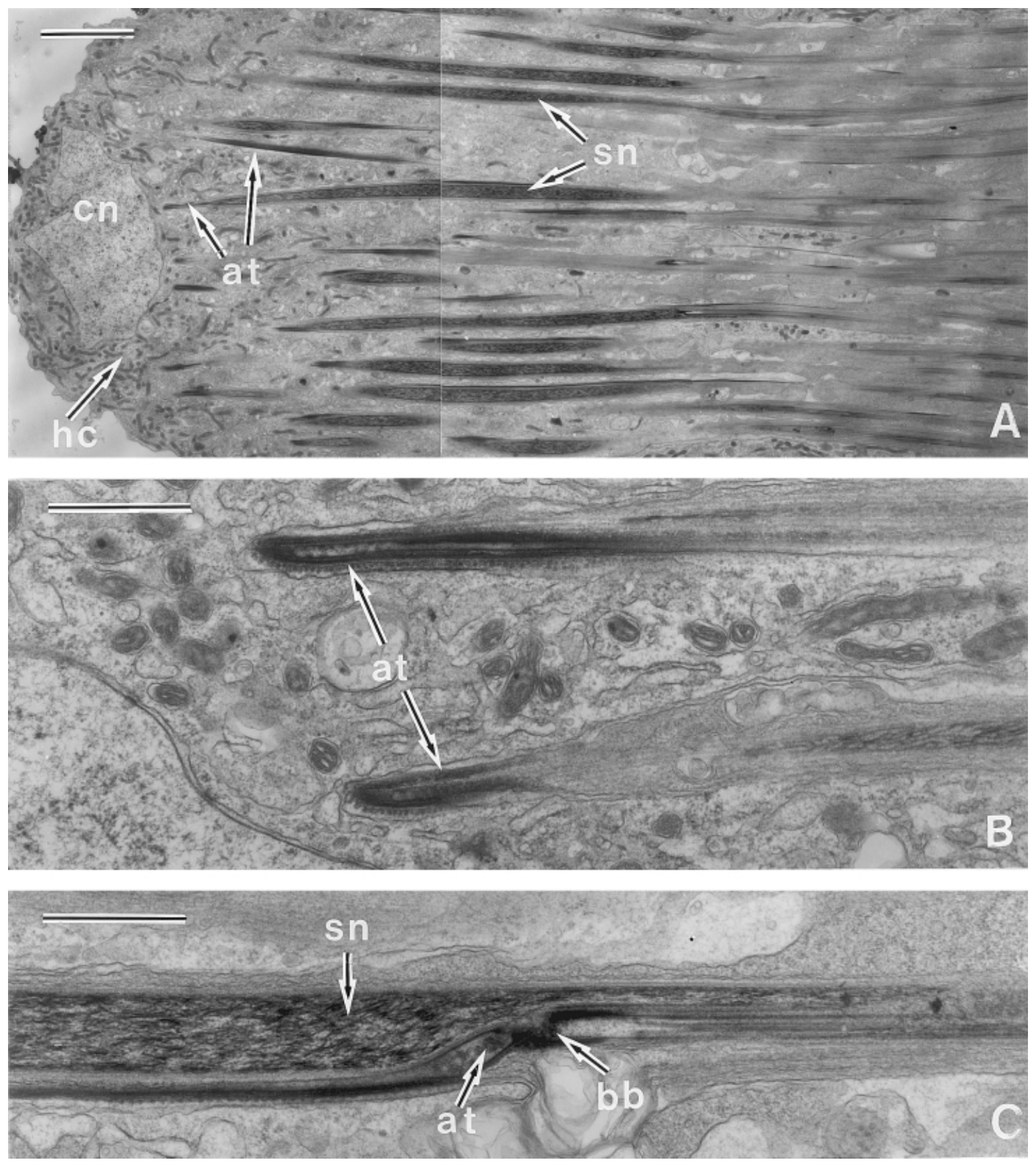

Figure 2 Electron micrographs of a diploid eupyrene sperm bundle at the early squeezing stage. $(A)$ The anterior region of a diploid sperm bundle. $(B)$ The anterior part of acrosome tubules penetrating into the head cyst cell displayed at a higher magnification. (C) The acrosome tubule-basal body connection of diploid sperm bundle displayed at a higher magnification. The basal body is attached to the nucleus and the acrosome tubule is connected to the basal body. at, acrosome tubule; bb, basal body; cn, cyst cell nucleus; hc, head cyst cell; sn, sperm nucleus. Scale bars represent: $(A), 4 \mu \mathrm{m} ;(B)$ and $(C), 1 \mu \mathrm{m}$.

\section{Opposite}

Figure 1 Confocal microscopic images of the spermatocytes at anaphase of meiosis II $(A-D)$ and sperm bundles $(E-J)$ stained by immunofluorescence for tubulin (green) and propidium iodide for nuclei (red). (A) Diploid eupyrene spermatocytes. (B) Diploid apyrene spermatocytes. $(C)$ Triploid eupyrene spermatocytes. (D) Triploid apyrene spermatocytes. (E) The anterior region of a diploid sperm bundle at the peristaltic squeezing stage. $(F)$ The posterior end of a diploid sperm bundle at the peristaltic squeezing stage. Cytoplasmic debris is discarded. $(G)$ The anterior region of a triploid eupyrene sperm bundle at the early squeezing stage. Some of the sperm nuclei (red) remain. $(H)$ The anterior region of a triploid eupyrene sperm bundle. Recession of the sperm nuclei is proceeding. (I) The anterior region of a triploid eupyrene sperm bundle. The shape of the sperm nuclei changes in the process of the recession. $(J)$ The posterior end of a triploid eupyrene sperm bundle. Sperm nuclei and nuclear fragments are contained in the debris. cc, cyst cell; d, debris; hc, head cyst cell; sn, sperm nucleus. Scale bars represent $20 \mu \mathrm{m}$. 

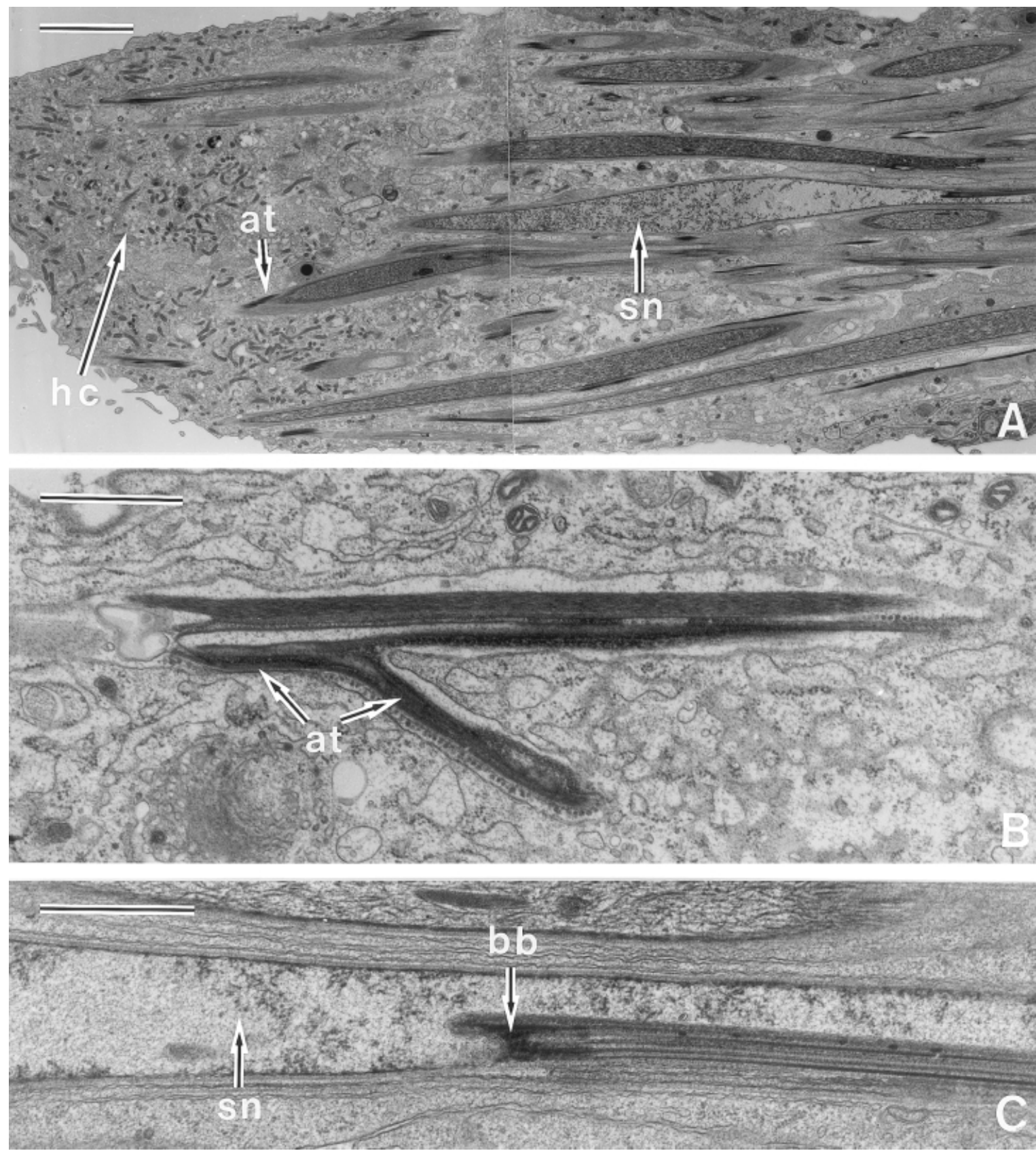

Figure 3 Electron micrographs of a triploid sperm bundle. $(A)$ The anterior region of a triploid sperm bundle in the corresponding stage to the bundle shown in Fig. 2A. Sparse distribution of acrosome tubules is shown. Nuclei recede from the apical surface of the bundle. $(B)$ The anterior region of an acrosome tubule branching and extending in the reverse direction. (C) A basal body without acrosome connection displayed at a higher magnification. The contents of nucleus are rough compared with the diploid. at, acrosome tubule; bb, basal body; hc, head cyst cell; sn, sperm nucleus. Scale bars represent: $(A), 4 \mu \mathrm{m}$; $(B)$ and $(C), 1 \mu \mathrm{m}$.

indistinct (Fig. 4B) in a round nucleus. Fig. 4C and D are serial sections of a basal body that lost its attachment to the nucleus as well as an acrosome tubule.

\section{Discussion}

Silkworm males produce dimorphic sperm from bipotential spermatogonia: nucleate eupyrene sperm and anucleate apyrene sperm. The two types are quite different in their morphology and functions. Eupyrene sperm are ordinary sperm to fertilise the eggs, while the functions of apyrene sperm are still a matter of debate (Friedländer, 1997; Jamieson, 1987; Jamieson et al., 1999).

Triploid silkworm males are highly sterile, as shown in Table 1. Morphological observation of triploid spermatogenesis in this study revealed that the 

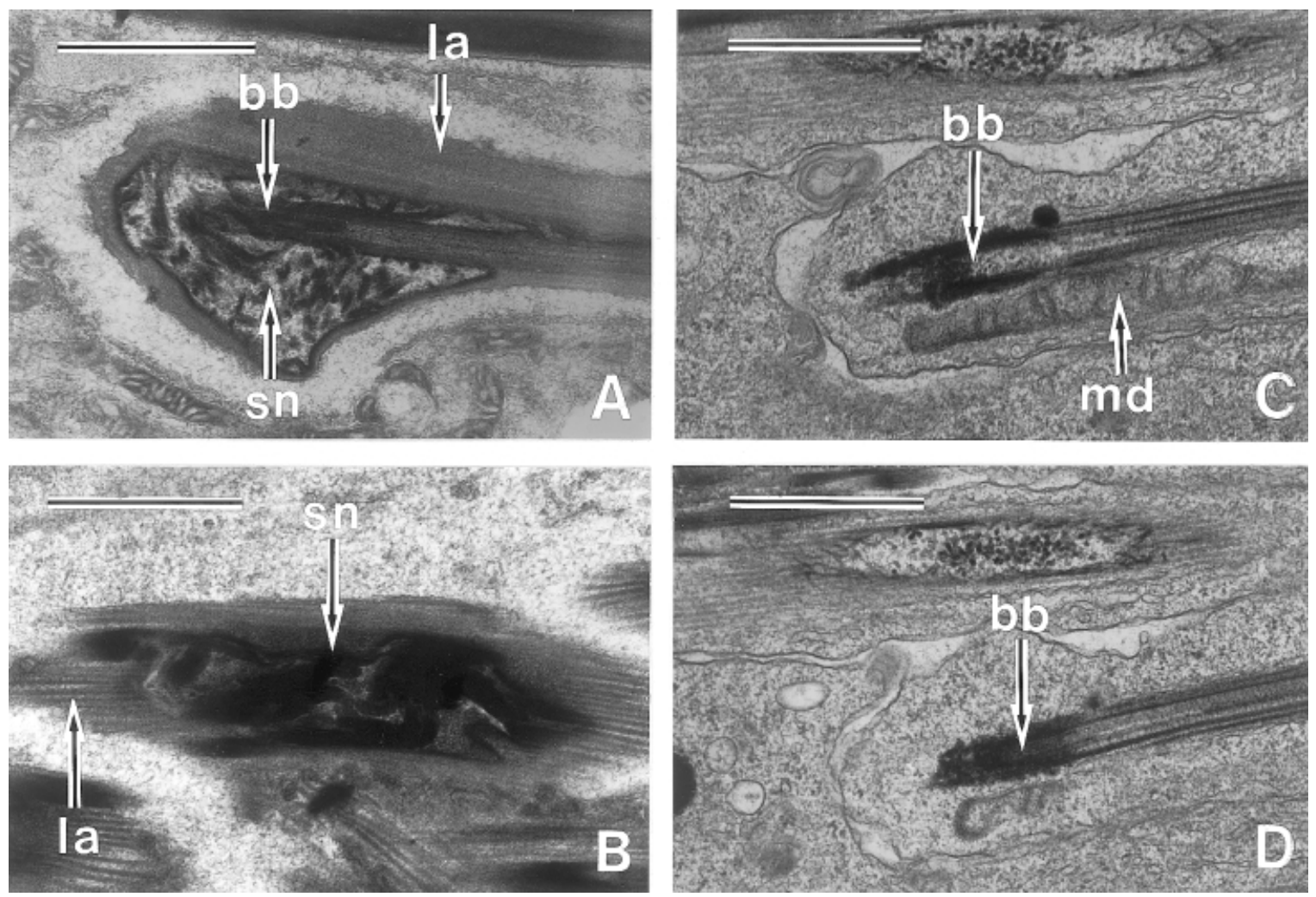

Figure 4 Electron micrographs of the nucleus $(A, B)$ and a basal body $(C, D)$ in the middle region of a triploid eupyrene sperm bundle shortly before adult emergence. $(A)$ A nuclear fragment with chromatin condensed. (B) A nuclear fragment in which the chromatin becomes indistinct. $(C),(D)$ Serial sections of a basal body which loses its connection with the nucleus. bb, basal body; la, lacinate appendage; md, mitochondrial derivative; sn, sperm nucleus. Scale bars represent $1 \mu \mathrm{m}$.

nuclei of the eupyrene sperm bundle recede towards the posterior and are finally eliminated by peristaltic squeezing. Confocal images by immunostaining of the triploid eupyrene spermatogenesis at the squeezing stage are confirmed by TEM observation. As shown in Figs. 3 and 4, TEM observations in this study disclose what happens in the triploid eupyrene sperm bundles. In triploid bundles: (1) acrosome tubules become abnormal, (2) the normal connection between an acrosome tubule and a basal body is disturbed, (3) a basal body is separated from the nucleus, (4) the nuclei are broken into fragments just as seen in apoptotic cells, and (5) the fragmented nuclei are ejected from the bundles by peristaltic squeezing while the axonema remain intact. Triploid silkworm spermatocytes exhibit disproportionate chromosome separation at meiosis I and II, and consequently, aneuploid nuclei are produced. Sado (1963) irradiated silkworm larvae with X-rays and obtained males that were highly sterile. He also observed the movement of the nuclei in the sperm bundle towards the posterior. The high sterility is also revealed in tetraploid silkworm males (Kawamura et al., 1995). Elimination of eupyrene sperm nuclei at a very late stage of spermatogenesis occurs not only in the triploid but also in the tetraploid (data not shown). It is reasonable to consider that the elimi- nation of eupyrene sperm nuclei by peristaltic squeezing causes the high sterility in polyploid males. A common factor in triploid and tetraploid sperm cells is the formation of chromosome bridges at the time of meiotic division (Fig. 1C; Kawamura, 1994). Such irregularity in meiotic division is observed in apyrene meiosis of any ploidy. Since apyrene sperm are not equipped with an acrosome tubule, the nuclei are not anchored to the head cyst cell (Yamashiki \& Kawamura, 1997) and, therefore, they are eliminated by the squeezing action. On the other hand, an acrosome tubule is formed in triploid eupyrene sperm cells though it shows abnormality.

It is widely accepted that irradiation damages chromosomes or genomes. However, we do not have sufficient information to elucidate what it is in the eupyrene spermatocytes that senses the abnormality in genomes, how the acrosome tubule becomes abnormal in the triploid, and why the sperm nuclei with abnormal genomes such as the triploid, the tetraploid or irradiated spermatocytes, fail to anchor the head cyst cell and are to be eliminated.

In the silkworm, both eupyrene and apyrene sperm are transferred into the female reproductive organs by copulation (Friedländer \& Gitay, 1972). Abnormal sperm genomes such as those of the apyrene or poly- 
ploid are not considered suitable to be involved in fertilisation. Damage to DNA or a genome can easily be induced by naturally occurring environmental factors, even during meiosis of the diploid (Katsuno, 1976). If abnormal nuclei should develop into fertilisable sperm, the influence on the succeeding generations would not be small. Therefore, silkworms may have a monitoring system to detect the damage, and may prepare subsequent pathways to disturb the formation of a normal acrosome tubule-basal body assembly. One of the purposes of peristaltic squeezing seems to be the elimination of such irregular nuclei of eupyrene sperm, in addition to the ejection of apyrene sperm nuclei. It seems amazing that the silkworm has established a crisis management system in spermatogenesis by adopting such a simple mechanism as peristaltic squeezing.

\section{References}

Cook, P.A. \& Wedell, N. (1999). Non-fertile sperm delay female remating. Nature 397, 486.

Friedländer, M. (1997). Control of the eupyrene-apyrene sperm dimorphism in Lepidoptera. J. Insect Physiol. 43, 1085-92.

Friedländer, M. \& Gitay, H. (1972). The fate of the normalanucleated spermatozoa in inseminated females of the silkworm, Bombyx mori. J. Morphol. 138, 121-30.

Gillies C.B. (1989). Chromosome pairing and fertility in polyploids. In Fertility and Chromosome Pairing: Recent Studies in Plant and Animals, ed. C.B. Gillies, pp. 137-76. Boca Raton, Florida: CRC Press.

Jamieson, B.G.M. (1987). The Ultrastructure and Phylogeny of Insect Spermatozoa, pp. 249-71. Cambridge: Cambridge University Press.

Jamieson, B.G.M., Dallai, R. \& Afzelius, B.A. (1999). Insects: Their Spermatozoa and Phylogeny, pp. 393-480. New Hampshire: Science Publishers.

Katsuno S. (1976). Abnormal sperm bundles in the silkworm, Bombyx mori. J. Seric. Sci. Jpn. 45, 528-32.

Kawaguchi, E. (1936). Der Einfluss der Eierbehandlung mit Zentifugierung auf die Vererbung bei dem Seidenspinner: I. Über experimentelle Auslösung der polyploiden Mutation. J. Fac. Agr. Hokkaido Imp. Univ. 38, 111-33.

Kawamura, N. (1978). The early embryonic mitosis in normal and cooled eggs of the silkworm, Bombyx mori. J. Morphol. 158, 157-72.
Kawamura, N. (1979). Polyploidy and size of serosa nuclei and cells in eggs of the silkworm, Bombyx mori. J. Seric. Sci. Jpn. 48, 77-85.

Kawamura, N. (1994). Male meiosis in polyploid silkworms, Bombyx mori L. (Lepidoptera: Bombycidae). Int. J. Insect Morphol. Embryol. 23, 311-17.

Kawamura, N., Sahara, K. \& Iizuka, T. (1995). Increase of fertility in tetraploid male silkworm by starvation. Hereditas 122, 119-23.

Kawamura, N., Yamashiki, N. \& Bando, H. (1998). Behavior of mitochondria during eupyrene and apyrene spermatogenesis in the silkworm, Bombyx mori, investigated by fluorescence in situ hybridization and electron microscopy. Protoplasma 202, 223-31.

Kawamura, N., Yamashiki, N. Saitoh, H. \& Sahara, K. (2000). Peristaltic squeezing of sperm bundles at the late stage of spermatogenesis in the silkworm, Bombyx mori. J. Morphol. 246, 53-8.

Lokki, J. \& Saura, A. (1980). Polyploid in insect evolution. In Polyploidy: Biological Relevance, ed. W.H. Lewis, pp. 269-73. New York: Plenum Press.

Muller, H.J. (1925). Why polyploidy is rare in animal than in plant. Am. Nat. 59, 346-53.

Sado T. (1963). Spermatogenesis of the silkworm and its bearing on radiation induced sterility. J. Fac. Agr. Kyushu Univ. 12, 359-404.

Sahara, K., Kawamura, N. \& Iizuka, T. (1990). Analysis of sex chromosome pairings in tetraploid females of the silkworm by using the sex-linked recessive gene. J. Seric. Sci. Jpn. 59, 196-201.

Takemura, Y., Kanda, T. \& Horie, Y. (1999). Artificial insemination using trypsin-treated sperm in the silkworm, Bombyx mori. J. Insect Physiol. 45, 471-7.

Tazima, Y. (1964). The Genetics of the Silkworm, pp. 165-75. London: Logos Press.

Wolf, K.W. \& Bastmeyer, M. (1991). Cytology of Lepidoptera. VI. Immunolocalization of microtubules in detergentextracted apyrene spermatocytes of Ephestia kuehniella Z. Eur. J. Cell Biol. 55, 238-47.

Yamashiki, N. \& Kawamura, N. (1997). Behaviors of nucleus, basal bodies and microtubules during eupyrene and apyrene spermiogenesis in the silkworm, Bombyx mori (Lepidoptera). Dev. Growth Differ. 39, 311-17.

Yamashiki, N. \& Kawamura, N. (1998). Behavior of centrioles during meiosis in the male silkworm Bombyx mori (Lepidoptera). Dev. Growth Differ. 40, 619-30. 